\title{
NFAT5/STAT3 interaction mediates synergism of high salt with IL-17 towards induction of VEGF-A expression in breast cancer cells
}

\author{
SUNEETHA AMARA $^{1}$, DALAL ALOTAIBI ${ }^{2}$ and VENKATASWARUP TIRIVEEDHI ${ }^{2}$ \\ ${ }^{1}$ Department of Medicine, Mercy Hospital, St. Louis, MO 63141; \\ ${ }^{2}$ Department of Biological Sciences, Tennessee State University, Nashville, TN 37209, USA
}

Received November 25, 2015; Accepted May 23, 2016

DOI: $10.3892 / \mathrm{ol} .2016 .4713$

\begin{abstract}
Chronic inflammation has been considered an important player in cancer proliferation and progression. High salt (sodium chloride) levels have been considered a potent inducer of chronic inflammation. In the present study, the synergistic role of high salt with interleukin (IL)-17 towards induction of the inflammatory and angiogenic stress factor vascular endothelial growth factor (VEGF)-A was investigated. Stimulation of MCF-7 breast cancer cells with high salt $(0.2 \mathrm{M} \mathrm{NaCl})$ and sub-minimal IL-17 $(1 \mathrm{ng} / \mathrm{ml})$ enhanced the expression of VEGF-A (2.9 and 2.6-fold, respectively, $\mathrm{P}<0.05$ ) compared with untreated cells. Furthermore, co-treatment with both high salt and sub-minimal IL-17 led to a 5.9-fold increase in VEGF-A expression $(\mathrm{P}<0.01)$, thus suggesting a synergistic role of these factors. VEGF-A promoter analysis and specific small interfering RNA knock-down of transcription factors revealed that high salt induced VEGF-A expression through nuclear factor of activated T-cells (NFAT)5, while IL-17 induced VEGF-A expression via signal transducer and activator of transcription (STAT)3 signaling mechanisms. Treatment of normal human aortic endothelial cells with the supernatant of activated MCF-7 cells enhanced cell migration and induced expression of migration-specific factors, including vascular cell adhesion protein, $\beta 1$ integrin and cluster of differentiation 31 . These data suggest that high salt levels synergize with pro-inflammatory IL-17 to potentially induce cancer progression and metastasis through VEGF-A expression. Therefore, low-salt diet, anti-NFAT5 and anti-STAT3 therapies may provide novel avenues for enhanced efficiency of the current cancer therapy.
\end{abstract}

Correspondence to: Dr Venkataswarup Tiriveedhi, Department of Biological Sciences, Tennessee State University, 3500 John A. Merritt Blvd., Nashville, TN 37209, USA

E-mail: vtirivee@tnstate.edu

Key words: inflammation, interleukin-17, breast cancer, NFAT5, cell migration

\section{Introduction}

A causal interlink between inflammation and cancer was first suggested in the 19th century by Rudolf Virchow (1). Accumulating evidence over several decades has delineated underlying molecular mechanisms between chronic inflammation and cancer progression (2). Multiple studies have proposed that inflammation-induced genetic instability promotes tumor progression (2). Inflammation also causes defective immune surveillance and responses to anti-cancer chemotherapy (3). Chronic inflammation in the tumor microenvironment induces the production of free radicals such as reactive oxygen and nitrogen species, leading to oxidative damage and nitration of DNA bases, which increases the risk of cancer initiation (4). One of the key features of cancer progression and metastasis is markedly enhanced inflammatory stress factors in the tumor microenvironment (5).

One of the events linking inflammation and cancer is an increase in inflammatory cytokines, including tumor necrosis factor (TNF) $\alpha$, interleukin (IL)- 6 and IL-17, and stress growth factors such as vascular endothelial growth factor (VEGF), in the tumor microenvironment (6). The pro-tumorigenic role of IL-17, an inflammatory cytokine, has also been implicated in several types of cancer (7). In mice with carcinogen-induced skin tumors, deficient expression of IL-17 receptor resulted in a lower tumor incidence and a diminished tumor size (8). Typically, inflammatory cytokines induce their effect by activating inflammatory transcription factors such as the Janus kinase (JAK)/signal transducer and activator of transcription (STAT) signaling pathway (9). Along with cytokines, chronic inflammation-induced stress molecules such as VEGF are known to be involved in cell proliferation, cell adhesion, inflammatory cell recruitment, angiogenesis and cell migration, leading to cancer progression (10). Specifically, the functions of VEGF in cancer are not limited to angiogenesis alone (11). VEGF-mediated signaling occurs in tumor cells and is known to contribute to key aspects of tumorigenesis, including cancer initiation and progression through its interaction with specific receptors, leading to the regulation of trafficking and secretion of other chemokines and extracellular matrix proteins (11).

A wide variety of environmental and infectious agents have been attributed to increased risk of inflammation-induced 
cancer progression (12). Dietary high salt intake has been correlated with an increase in the incidence of cancers (13). Traditionally, high salt levels have been correlated with cardiovascular disease and inflammatory injury in arteries (14). In animal models, high sodium chloride levels have been demonstrated to cause excessive inflammatory activation, triggering ischemia injury and end-organ stress mediated by reactive oxygen species and pro-inflammatory cytokine secretion, leading to irreversible cardiac cell damage $(15,16)$. Importantly, in the context of breast cancer, the sodium content of mammary adenocarcinomas has been reported to be significantly higher than in the normal mammary epithelium (17). However, in that study, it was not clear if the increased sodium content observed was intracellular or extracellular. Human studies on gastric cancer suggested that excess sodium could cause inflammation and stomach ulcers, which could lead to gastric cancer (18). It is also important to understand that high sodium content in mammary adenocarcinomas has been shown to be significantly higher than that of normal lactating mammary epithelium (19). Furthermore, a correlation between expression of sodium symporters and increased invasion capacity of breast cancer has been previously suggested (20-22). In the present study, the synergistic effect of high sodium chloride levels with pro-inflammatory cytokines towards induction of the expression of VEGF-A, a crucial inflammatory and angiogenic stress factor that is important in tumor progression and metastasis, is reported.

\section{Materials and methods}

Cell culture. The breast cancer cell line MCF-7 (HTB-22 $2^{\mathrm{TM}}$ ) and normal human aortic endothelial cells (NHAECs; PCS-100-011 ${ }^{\mathrm{TM}}$ ) were obtained from the American Type Culture Collection (ATCC; Manassas, VA, USA) and cultured in cell basal essential medium (30-2003; ATCC) along with the medium supplements recommended by the manufacturer. For stimulation studies, breast cancer cells were treated with varying concentrations $(0-1,000 \mathrm{ng} / \mathrm{ml})$ of IL-17 (Thermo Fisher Scientific, Inc., Waltham, MA, USA) or sodium chloride supplement (0.2 M final concentration; Sigma-Aldrich, St. Louis, MO, USA) for $48 \mathrm{~h}$. It is important to note that sodium chloride concentration in regular cell culture basal medium is $0.1 \mathrm{M}$. Therefore, to perform high salt studies $(0.2 \mathrm{M})$, the basal medium was supplemented with additional $0.1 \mathrm{M} \mathrm{NaCl}$ to achieve a final concentration of 0.2 M. Specific small interfering (si)RNA (Santa Cruz Biotechnology, Inc., Dallas, TX, USA) mediated gene knock-down of STAT3 (sc-29493) and NFAT5 (sc-43968). The knock-down efficiency was measured by reverse transcription-quantitative polymerase chain reaction (RT-qPCR), and non-specific siRNA (sc-37007) was used as a negative control. All experiments were performed in triplicate.

Western blot analysis. Western blot analysis was performed as described previously $(23,24)$. All primary and secondary antibodies were obtained from Santa Cruz Biotechnology, Inc., unless mentioned otherwise. All primary antibodies were diluted to 1:200 and all secondary antibodies were diluted to 1:1,000. The following specific primary antibodies against VEGF-A (sc-152), STAT3 (sc-482), STAT5 (sc-835), NFAT1 (sc-7294), NFAT5 (sc-13035), vascular cell adhesion protein
(VCAM; sc-8304), $\beta 1$ integrin (sc-9970) and actin (sc-10731) were utilized. Phosphorylated proteins were probed with the phospho (p)-specific primary antibodies Ser-727-p-STAT3 (sc-21876) and Ser-155-p-NFAT5 (SAB4504718) (Sigma-Aldrich). The nitrocellulose membranes were developed using a chemiluminescence kit (EMD Millipore, Billerica, MA, USA) and analyzed using Universal Hood II (Bio-Rad Laboratories, Inc., Hercules, CA, USA). Densitometric analysis was performed using ChemiDoc XRS systems software provided by Bio-Rad Laboratories, Inc.

Messenger ( $m$ )RNA expression analysis. The expression profiles of intracellular signaling genes in MCF-7 cells were analyzed using fluorescein amidite-labeled RT-qPCR primers for VEGF-A (Hs03929036_s1), NFAT5 (Hs00232437_m1), STAT3 (Hs01051722_s1), glyceraldehyde 3-phosphate dehydrogenase (GAPDH; Hs402869) and actin (Hs4333762T), which were obtained from Applied Biosystems (Thermo Fisher Scientific, Inc.), according to the manufacturer's protocol (25). Briefly, total RNA was extracted from $10^{6}$ cells using TRIzol reagent (Sigma-Aldrich). RNA samples were quantified by their absorbance at $260 \mathrm{~nm}$. The RNA was reverse transcribed, and qPCR was subsequently performed in a final reaction volume of $50 \mu \mathrm{l}$ using LightCycler ${ }^{\circledR} 480$ Probes Master (Roche Diagnostics, Indianapolis, IN, USA). Each sample was analyzed in triplicate. Cycling conditions consisted of an initial denaturation of $95^{\circ} \mathrm{C}$ for $15 \mathrm{~min}$, followed by 40 cycles of $95^{\circ} \mathrm{C}$ for $30 \mathrm{sec}$, followed by annealing/extension at $61^{\circ} \mathrm{C}$ for $1 \mathrm{~min}$. Expression data were quantified using the $2^{-\Delta \Delta \mathrm{Cq}}$ method (26) and normalized to GAPDH expression.

Immunofluorescence microscopy. For staining of VEGF-A, 50,000 MCF7 cells were grown on coverslips in 24-well plates (19). Cells were fixed with $4 \%$ paraformaldehyde (23). Normal 2\% goat serum in Dulbecco's phosphate-buffered saline (Thermo Fisher Scientific, Inc.) with $1 \%$ bovine serum albumin (Sigma-Aldrich) and $0.1 \%$ Tween 20 was used for blocking and washing. The aforementioned specific anti-VEGF-A primary antibody and a phycoerythrin-conjugated antibody (cat no. 12-4739-81; eBioscience, Inc., San Diego, CA, USA) were used for immunofluorescence, with primary antibodies diluted to 1:10 and secondary antibodies diluted to 1:40. The images were captured using an Eclipse 80i fluorescence microscope (Nikon Corporation, Tokyo, Japan) and processed using Metamorph version 6.3r2 software (Molecular Devices, LLC, Sunnyvale, CA, USA).

Plasmid constructs and luciferase reporter assay. For the reporter constructs, the VEGF-A promoter regions $(-2,000$ to +50 bp) were amplified from human genomic DNA (Zyagen, San Diego, CA, USA) by PCR using iProof ${ }^{\text {TM }}$ High-Fidelity DNA Polymerase (Bio-Rad Laboratories, Inc.) (23). The PCR products were subcloned into the pGL4.11[luc2P] vector (Promega Corporation, Madison, WI, USA) upstream of a luciferase gene using appropriate restriction sites. Putative transcription factor binding sites were identified with the Transcription Element Search System (TESS) algorithm (http://www.cbil.upenn.edu/downloads/).

The transcription factor binding to the VEGF-A promoter was analyzed by luciferase assay as previously reported $(20,23)$. 
Briefly, MCF-7 cells $\left(1 \times 10^{5}\right)$ were transfected in 24-well plates with $1 \mu \mathrm{g}$ pGL4.11[luc2P] luciferase reporter vector driven by the VEGF-A promoter, or with $2 \mu \mathrm{g}$ control vector. For transfection of MCF-7 cells, $0.2 \times 10^{5}$ cells/well were seeded into a 24-well plate and grown for 24-48 h. Cells were harvested $48 \mathrm{~h}$ post-transfection, and efficiency was measured by qPCR, immunostaining and western blotting.

Chromatin-immunoprecipitation (ChIP) and co-immunoprecitation (Co-IP). ChIP and Co-IP were performed as previously described (20). For ChIP analysis to identify the binding regions of NFAT5 and STAT3, ChIP-IT Express kit (Active Motif,Inc., Carlsbad,CA, USA) was utilized according to the manufacturer's protocol and as previously described (23). Control immunoglobulin (Ig)Gs, anti-NFAT5 or anti-STAT3 $(1 \mu \mathrm{g})$ were used to immunoprecipitate the DNA-protein complexes. Specific VEGF-A promoter regions were amplified using PCR and resolved on $2 \%$ agarose gels. PCR cycling conditions consisted of an initial denaturation step at $95^{\circ} \mathrm{C}$ for $3 \mathrm{~min}$, followed by 35 cycles of $95^{\circ} \mathrm{C}$ for $30 \mathrm{sec}$, annealing at $60^{\circ} \mathrm{C}$ for $30 \mathrm{sec}$ and extension at $72^{\circ} \mathrm{C}$ for $1 \mathrm{~min}$. For NFAT5 and STAT3 Co-IP, proteins obtained from MCF-7 cells were subjected to sodium dodecyl sulfate polyacrylamide gel electrophoresis (4-12\% polyacrylamide gels) and immunoblotting. NFAT5 and STAT3 were detected with rabbit anti-NFAT5 and rabbit anti-STAT3 antibodies, respectively. The primary antibodies were diluted to 1:200 and secondary antibodies were diluted to $1: 1,000$

Enzyme-linked immunosorbent assay (ELISA). The secretory extracellular VEGF-A in the cell supernatant was quantitated by ELISA according to the manufacturer's protocol (R\&D Systems, Inc., Minneapolis, MN, USA) (21). Due to the limitation of the detection system, the supernatant was diluted 1:1,000 and quantified with a standard curve using the manufacturer-provided standards. Detection of the optical density value at $450 \mathrm{~nm}$ was performed using $\mathrm{EMax}^{\circledR}$ Plus Microplate Reader (Molecular Devices, LLC), and data analysis was conducted using SoftMax Pro GxP software (version 5.4) provided by Molecular Devices, LLC.

Cell migration assay. The migratory ability of NHAECs following stimulation with the supernatant isolated from various MCF-7-experimental cell culture conditions was performed using Cultrex ${ }^{\circledR}$ Cell Migration Assays (cat no. 3465-096-K; R\&D Systems, Inc.) according to the manufacturer's protocol. Briefly, serum-starved NHAECs were placed in the top chamber, and fresh 24-h supernatant collected from MCF-7 cells that had been subjected to various experimental cell culture conditions was placed in the bottom chamber, separated by a basement membrane-coated separation membrane. The migration ability was quantified following dissociation of the cells from the membrane with the appropriate dissociation buffers (provided in the Cultrex Cell Migration Assay) and colorimetrically analyzed at $595 \mathrm{~nm}$.

Flow cytometry. The expression of cluster of differentiation (CD)31 on NHAECs was analyzed by flow cytometry using appropriated primary and fluorescein isothiocyanate-labelled secondary antibodies (25). Samples were analyzed using a FACSCalibur/LSR II flow cytometer (BD Biosciences, Franklin Lakes, NJ, USA), and cell sorting was performed with a FACSVantage cell sorter (BD Biosciences). Data were analyzed using FACSDiva ${ }^{\mathrm{TM}}$ software (version 8.0.1; BD Biosciences). Gates were set according to isotype controls.

Statistical analysis. Data were expressed as the mean \pm standard error of the mean from four independent experiments. Statistical differences between the means were analyzed using a paired or unpaired Student's $t$ test. $\mathrm{P}<0.05$ was considered to indicate a statistically significant difference. All analyses were conducted using Origin version 7.0 (OriginLab, Northampton, MA, USA) or GraphPad version 5 software (GraphPad Software, Inc., LaJolla, CA, USA).

\section{Results}

Enhanced expression of VEGF-A following co-stimulation of MCF-7 cells with high sodium chloride and sub-minimal IL-17 levels. Although VEGF was initially considered to be a vascular permeability factor and an endothelial cell-specific mitogen, multiple lines of evidence convincingly suggest its critical role as an autocrine-signaling factor in solid tumors, including breast cancer (22). Previous studies have reported that IL-17 induces the expression of VEGF-A in solid tumors (27). In line with this evidence, preliminary experiments conduced by the present authors on MCF-7 breast cancer cells demonstrated a significantly higher expression of VEGF-A following stimulation with IL-17 at concentrations $>100 \mathrm{ng} / \mathrm{ml}$, but minimal response $(<20 \%)$ at concentrations $<10 \mathrm{ng} / \mathrm{ml}$ (data not shown). To determine the specific role of high sodium chloride levels (referred to as high salt) in a pro-inflammatory microenvironment, initial cell viability studies were performed, which demonstrated $<30 \%$ cell viability at $\mathrm{NaCl}$ concentrations $>0.25 \mathrm{M}$, while $>95 \%$ cell viability was maintained at 0.15 and $0.2 \mathrm{M} \mathrm{NaCl}$ in the culture medium (data not shown). Therefore, in all the experiments described in the present study, $0.2 \mathrm{M} \mathrm{NaCl}$ was used for high salt condition, and $1 \mathrm{ng} / \mathrm{ml} \mathrm{IL-17}$ was used for sub-minimal IL-17 concentration.

As VEGF-A is a key inflammatory stress molecule and biomarker, experiments were performed in the present study to determine the role of high salt synergising with the pro-inflammatory cytokine effect of IL-17 on the expression of VEGF-A protein. For that purpose, the breast cancer cell line $\mathrm{MCF}-7$ was treated with either high salt $(0.2 \mathrm{M} \mathrm{NaCl})$, IL-17 (1 ng/ml) or a combination of both. As shown in Fig. 1A, western blot analysis of the cellular extract from MCF-7 cells demonstrated an increased expression of VEGF-A following co-treatment with high salt and sub-minimal IL-17. This was further verified by intracellular immunocytochemical staining of MCF-7 cells for VEGF-A (Fig. 1B). Quantitative mRNA analysis of VEGF-A (Fig. 1C) demonstrated that, under basal conditions, there was minimal expression of VEGF-A mRNA transcript (2.1 \pm 0.6 -fold) compared with the GAPDH control transcript. However, following treatment with either high salt or sub-minimal IL-17 alone, there was a significant elevation of VEGF-A mRNA transcription $(6.1 \pm 1.3$ and $5.4 \pm 0.8$-fold, respectively, $\mathrm{P}<0.05)$. Co-treatment with both high salt and sub-minimal IL-17 demonstrated a 15.7 \pm 2.9 -fold 
increased VEGF-A transcript expression $(\mathrm{P}<0.05)$ over the basal conditions. These data were further confirmed by ELISA-based quantitative analysis of the supernatant from the aforementioned conditions to measure the secretion of VEGF-A protein by MCF-7 cells (Fig. 1D). Importantly, treatment with equimolar mannitol concentrations $(0.1 \mathrm{M}$ $\mathrm{NaCl}+0.1 \mathrm{M}$ mannitol) demonstrated no enhanced expression of VEGF-A (2.5 \pm 0.9 -fold, $\mathrm{P}>0.70)$ over basal conditions. These data indicate that high salt and IL-17 exert a synergistic effect. Furthermore, as the synergistic effect was higher than the individual conditions alone, these results strongly suggest a possibility of two different signaling mechanisms separately induced by high salt and IL-17.

Transcription factors NFAT5 and STAT3 induce VEGF-A expression following co-stimulation with high salt and IL-17. Based on the aforementioned findings (Fig. 1), experiments were performed to determine the transcription factors involved in the signaling events mediated by high salt and IL-17 that led to increased expression of VEGF-A. The present authors previously demonstrated that STAT3 mediates IL-17-induced pro-inflammatory signaling (23). NFAT5, also known as tonicity-responsive enhancer binding protein (TonEBP), which is a mediator of osmotic stress and immune regulation, has also been observed to be upregulated in breast cancer (28). Therefore, various transcription factors were initially analyzed by RT-qPCR, and NFAT5 and STAT3 demonstrated significantly enhanced expression following treatment with high salt and IL-17. The other transcription factors tested that did not induce a significant change under the current experimental conditions were NFAT1-4 and STAT1, -2, -4 and -6 (data not shown). Western blot and phosphoblot studies (Fig. 2A) demonstrated enhanced expression and phosphorylation of NFAT5 in MCF-7 cells following treatment with high salt $(0.2 \mathrm{M} \mathrm{NaCl})$ for $60 \mathrm{~min}$, while stimulation with sub-minimal IL-17 (1 ng/ml) enhanced the expression and phosphorylation of STAT3. However, co-treatment with high salt and sub-minimal IL-17 led to increased expression and phosphorylation of both NFAT5 and STAT3. Quantitative analysis by RT-qPCR demonstrated that there was a 3.4-fold upregulation of total and phosphorylated NFAT5 (Fig. 2B and C) following treatment with high salt, which did not increase further upon co-treatment with both high salt and sub-minimal IL-17. Similarly, there was a 3-fold upregulation in total and phosphorylated STAT3 levels (Fig. 2D and E) following treatment with sub-minimal IL-17, which did not increase further upon co-treatment with high salt and sub-minimal IL-17. These data support the earlier assertion that high salt and IL-17 potentially induce VEGF-A expression through two different signaling pathways.

To confirm that high salt and IL-17 induce separate signaling pathways that result in the induction of VEGF-A expression, siRNA knockdown experiments specific for NFAT5 and STAT3 were performed. Western blot analysis (Fig. 2F) demonstrated that siRNA knock-down of NFAT5 and STAT3 individually, following co-treatment with high salt and sub-minimal IL-17, led to reduced intracellular expression of VEGF-A. As expected, combined knock-down of both NFAT5 and STAT3 synergistically diminished VEGF-A expression. This was further verified by immunocytochemical analysis (Fig. 2G). Quantitative ELISA-based analysis of VEGF-A secretion (Fig. 2I) demonstrated that NFAT knock-down reduced VEGF expression to $137 \pm 49 \mathrm{pg} / \mathrm{ml}$, while STAT3 knock-down reduced VEGF expression to $152 \pm 41 \mathrm{pg} / \mathrm{ml}$ in high salt and sub-minimal IL-17-co-treated MCF-7 cells, where VEGF-A expression was $562 \pm 73 \mathrm{pg} / \mathrm{ml}$ prior to treatment. Taken together, these data confirm that high salt and IL-17 induce two different signaling mechanisms leading to enhanced expression of the inflammatory stress molecule VEGF-A.

NFAT5 and STAT3 bind to the VEGF-A promoter region at $-1,471$ and -840 bp upstream of the open reading frame. To determine the role of high salt and IL-17 in VEGF-A gene transcription, the luciferase reporter construct containing the $-2,000$ to +50 bp region of the human VEGF-A gene promoter was transfected into MCF-7 breast cancer cells. These luciferase-transfected cells were treated with either high salt, sub-minimal IL-17 or both, and luciferase activity was recorded. An increase in VEGF-A reporter activity was observed following individual stimulation with high salt (7.2-fold, Fig. 3A) and sub-minimal IL-17 (6.4-fold, Fig. 3B) over control null-luciferase vector-transfected cells. Further co-treatment with both high salt and sub-minimal IL-17 produced a 25.2-fold increase (Fig. 3C) in luciferase activity compared with untreated cells. These data were in line with the results described in Fig. 2, thus supporting the hypothesis that high salt and IL-17 work synergistically to enhance VEGF-A expression.

To specifically identify the putative DNA binding sequences for NFAT5 and STAT3 on the VEGF-A promoter, a computational analysis of the $-2,000$ to +50 bp region of the VEGF-A promoter was performed using TESS. This analysis identified two putative DNA binding sites for NFAT5 (TGGAAA at -1,471 and -1,809 bp) and two putative DNA binding sites for STAT3 (TTCCCAAA/TTTCCA AA at -840 and -622 bp) (Fig. 3A). To determine whether NFAT5 and STAT3 regulate VEGF-A expression in MCF-7 cells, these cells were transfected with the mutant VEGF-A promoter reporter construct and treated with high salt, IL-17 or both (Fig. 3A-C). As shown in Fig. 3A, following treatment with high salt, the putative NFAT5 binding site mutant construct $\left({ }^{*}-1,474-73\right.$, GA to $\left.{ }^{*} \mathrm{TC}\right)$ exhibited a significant decrease ( $\leq 66 \%$ loss of activity) in reporter activity compared with the native VEGF-A reporter activity. However, the other putative NFAT5 binding site mutant construct $\left({ }^{*}-1,812-11\right.$, GA to *TC) did not display any change in VEGF-A promoter activity, thus suggesting that the NFAT5 binding domain is located at $-1,471 \mathrm{bp}$ on the VEGF-A promoter. Similarly, following treatment with sub-minimal IL-17 (Fig. 3B), the putative STAT3 (TTCCCAAA or TTTCCAAA) binding mutant construct $\left({ }^{*}-843-842, \mathrm{CA}\right.$ to $\left.{ }^{*} \mathrm{TG}\right)$ exhibited a significant decrease $(\leq 71 \%$ loss of activity) in reporter activity compared with the native VEGF-A reporter activity, while the other putative STAT3 binding mutant construct ("-625-24, CA to ${ }^{*}$ TG) did not exhibit any change in VEGF-A promoter activity, thus suggesting that the putative STAT3 binding domain is located at $-1,471 \mathrm{bp}$. As expected, these two mutants demonstrated the highest loss of activity following co-treatment with high salt and sub-minimal IL-17 (Fig. 3C), thus strongly suggesting a synergistic mechanism of action 


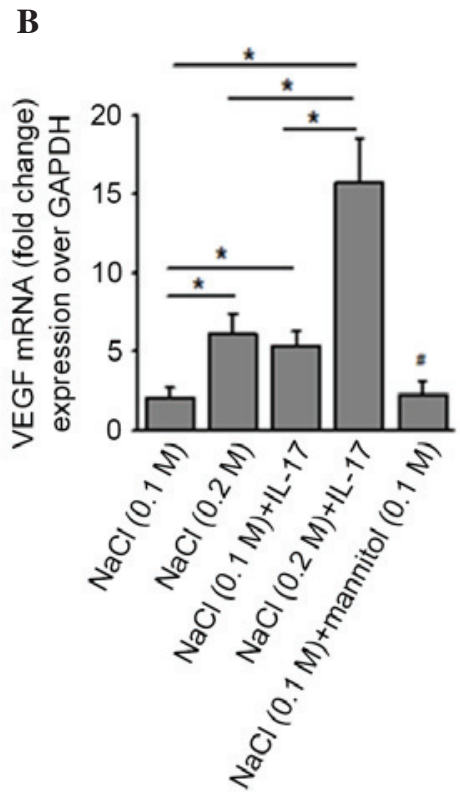

C
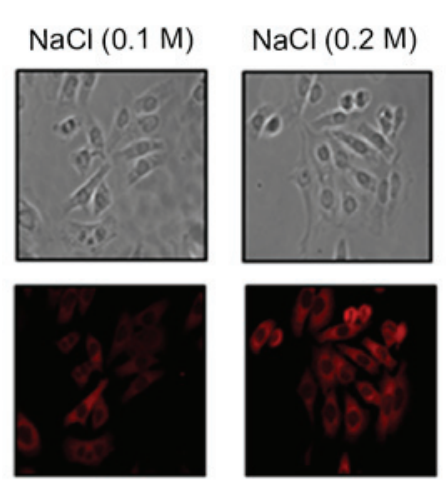

$\mathrm{NaCl}(0.1 \mathrm{M})$

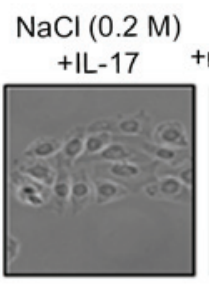

$\mathrm{NaCl}(0.1 \mathrm{M})$
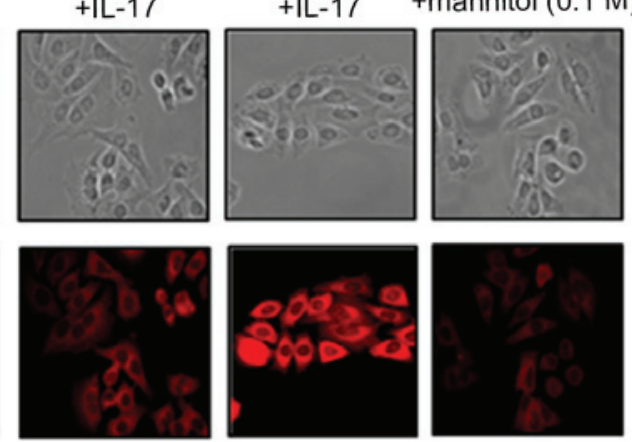

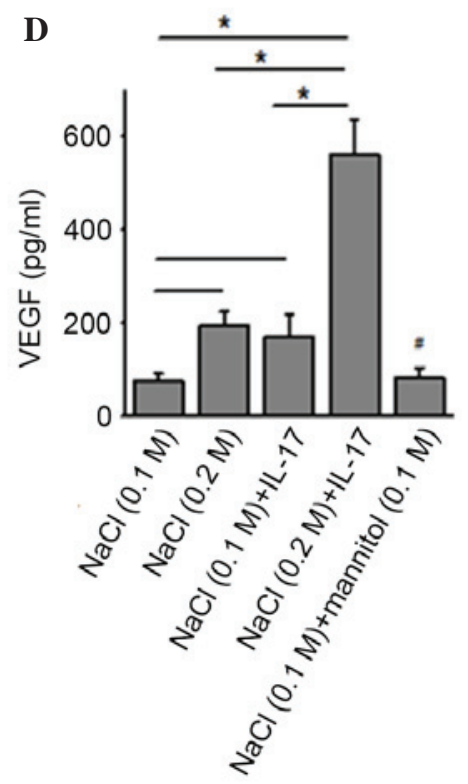

Figure 1. Induction of VEGF-A expression in MCF-7 breast cancer cells following stimulation with high salt and sub-minimal IL-17. (A) Western blot analysis of VEGF-A expression in MCF-7 cells following treatment with high salt $(0.2 \mathrm{M} \mathrm{NaCl})$, IL-17 ( $1 \mathrm{ng} / \mathrm{ml})$ or both $(0.2 \mathrm{M} \mathrm{NaCl} \mathrm{and} 1 \mathrm{ng} / \mathrm{ml} \mathrm{IL}-17)$. Of note, the regular complete medium used in the present study contained $0.1 \mathrm{M} \mathrm{NaCl}$, and equimolar mannitol $(0.1 \mathrm{M} \mathrm{NaCl}+0.1 \mathrm{M}$ mannitol $)$ was used as a negative control. The cell lysates were probed with appropriate primary and secondary antibodies. (B) Immunocytostaining of MCF-7 cells for VEGF-A. VEGF-A was probed with rabbit anti-human primary antibody at 1:100, and later probed with phycoerythrin-conjugated goat anti-rabbit secondary antibody at 1:200. (C) VEGF-A messenger RNA expression was analyzed by reverse transcription-quantitative polymerase chain reaction. Quantitation was performed by the $2^{-\triangle \Delta C \mathrm{q}}$ method and normalized to glyceraldehyde 3-phosphate dehydrogenase expression. (D) Enzyme-linked immunosorbent assay-based analysis of VEGF-A in the supernatant of the MCF-7 cells following treatment with the conditions mentioned above. Data are represented as mean values \pm standard error of the mean from four independent experiments. Statistical significance was analyzed with the Student's $t$ test, ${ }^{"} \mathrm{P}<0.05 ;{ }^{\#} \mathrm{P}>0.05$. VEGF, vascular endothelial growth factor; mRNA, messenger RNA; GAPDH, glyceraldehyde 3-phosphate dehydrogenase; IL, interleukin.

between NFAT5 and STAT3 transcription factors in regulating VEGF-A expression.

To determine whether NFAT5 and STAT3 bind to adjacent DNA binding sites on the VEGF-A promoter to form transcriptional-activation DNA-protein complexes, following high salt, IL-17 or combined treatment, MCF-7 cells were immunoprecipitated with anti-NFAT5, anti-STAT3 or control IgGs. The results of ChIP and PCR analysis using primers specific for the VEGF-A promoter regions -2,000 to $-1,751 \mathrm{bp}$, $-1,500$ to $-1,251 \mathrm{bp},-1,000$ to $-751 \mathrm{bp},-700$ to $-450 \mathrm{bp}$, and control primers for the -250 to +50 bp region of the actin promoter (Fig. 3E, black bars), demonstrated that NFAT5 and STAT3 bind to the VEGF-A promoter at the $-1,500$ to $-1,251 \mathrm{bp}$ and $-1,000$ to $-751 \mathrm{bp}$ regions, respectively (Fig. 3D). The DNA binding pattern of NFAT5 and STAT3 strongly correlates with the locations of the consensus binding sites on the VEGF-A promoter determined by luciferase reporter activity (Fig. 3A-C). ChIP with control IgGs did not enrich VEGF-A promoter regions, demonstrating the specificity for these transcription factors. No binding was observed in PCRs conducted with primers specific for the -250 to $+50 \mathrm{bp}$ region of the actin promoter, which lacks these binding sites 
A

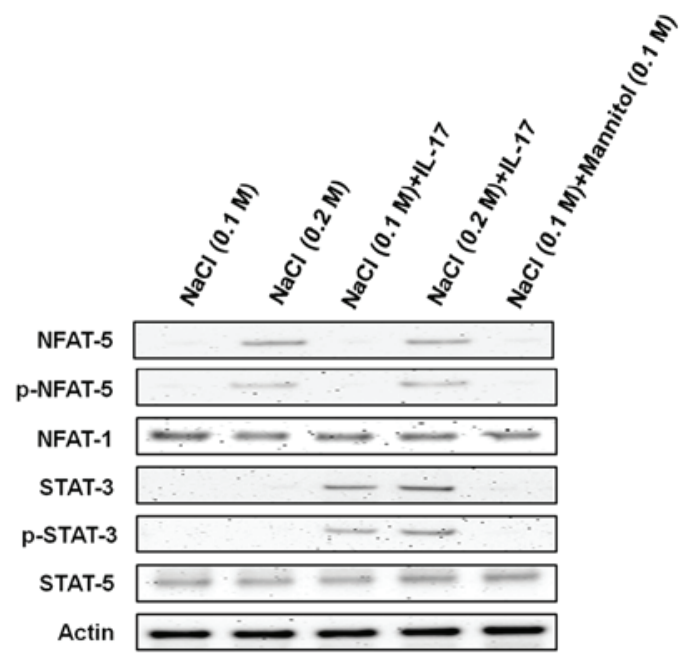

D

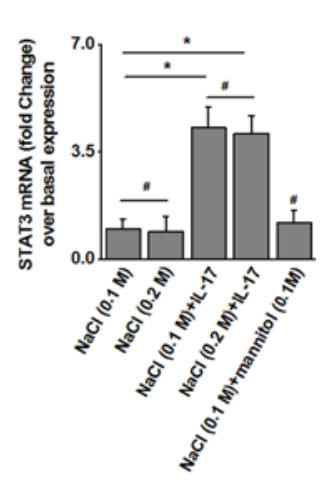

E

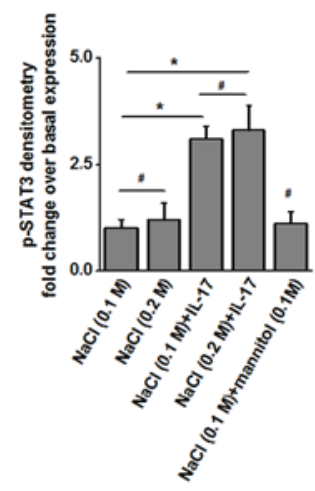

B

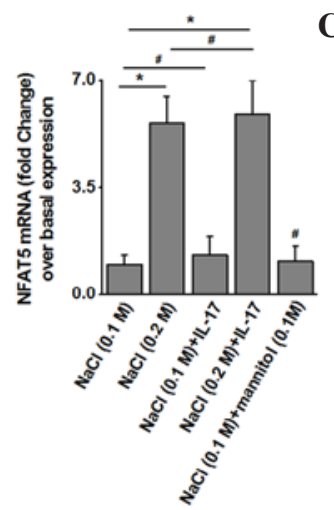

C

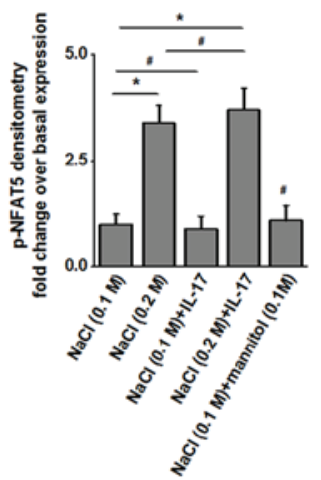

$\mathbf{F}$

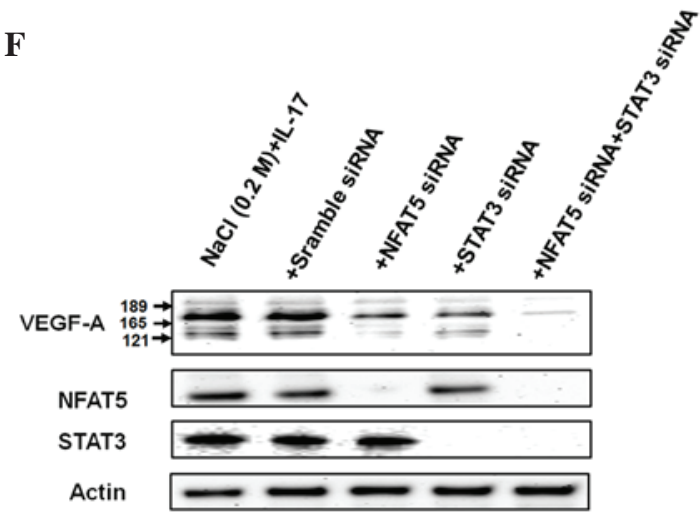

G
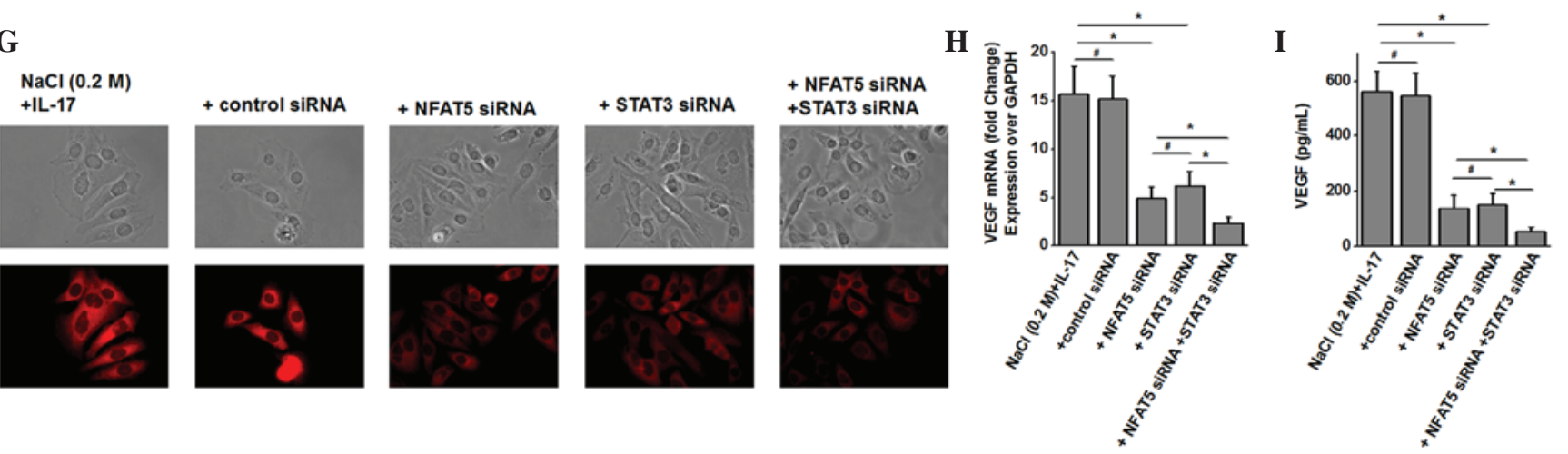

Figure 2. NFAT5 and STAT3 transcription factors were induced in MCF-7 cells following stimulation with high salt and sub-minimal IL-17, respectively. (A) Western blot analysis was performed to determine the protein expression levels of NFAT5 (170 kDa), p-NFAT5 (170 kDa), NFAT1 (140 kDa), STAT3 $(86 \mathrm{kDa})$, p-STAT3 $(86 \mathrm{kDa})$, STAT5 $(92 \mathrm{kDa})$ and actin $(43 \mathrm{kDa})$, both total and active phosphorylated forms, after 30 min of stimulation with high salt, sub-minimal IL-17 or both. Quantitative mRNA expression of (B) NFAT5, (C) STAT3, (D) p-NFAT5 and (E) p-STAT3 by RT-qPCR was analyzed after 60 min of stimulation with high salt, sub-minimal IL-17 or both. Quantitation was performed with the $2^{-\Delta \Delta C q}$ method normalized to GADPH expression. (F) Western blot analysis of VEGF-A expression in MCF-7 cells following stimulation with high salt and IL-17, along with NFAT5 and STAT3 knock-down by specific siRNA. Scrambled siRNA was used as negative control. Specific NFAT5 and STAT3-siRNA treatment resulted in decreased expression of NFAT5 and STAT3 transcription factors, respectively. (G) Immunocytostaining of MCF-7 cells for VEGF-A following treatment with both high salt and sub-minimal IL-17, and specific siRNA knock-down of NFAT5 and STAT3. (H) VEGF-A mRNA expression was analyzed by RT-qPCR in MCF-7 cells following stimulation with high salt and IL-17, along with NFAT5 and STAT3 knock-down by specific siRNA. Quantitation was performed with the $2^{-\triangle \Delta C q}$ method normalized to GADPH expression. (I) Enzyme-linked immunosorbent assay-based analysis of VEGF-A in the supernatant collected from MCF-7 cells following stimulation with high salt and IL-17, along with NFAT5 and STAT3 knock-down by specific siRNA. Data are represented as mean values \pm standard error of the mean from four independent experiments. Statistical significance was analyzed by the Student's $t$ test, "P< $<0.05$; ${ }^{P} \mathrm{P}>0.05$. VEGF, vascular endothelial growth factor; mRNA, messenger RNA; GAPDH, glyceraldehyde 3-phosphate dehydrogenase; IL, interleukin; NFAT, nuclear factor of activated T-cells; STAT, signal transducer and activator of transcription; p-, phosphorylated; siRNA, small interfering RNA; RT-qPCR, reverse transcription-quantitative polymerase chain reaction.

(Fig. 3D). Furthermore, the protein-protein complexes were immunoprecipitated (Fig. 3E) and probed with anti-STAT3 or anti-NFAT5 antibodies on western blotting. This supported the ChIP findings that NFAT5 and STAT3 were complexed together on the VEGF-A promoter. Taken together, these data clearly demonstrate that the transcription factors NFAT5 
A

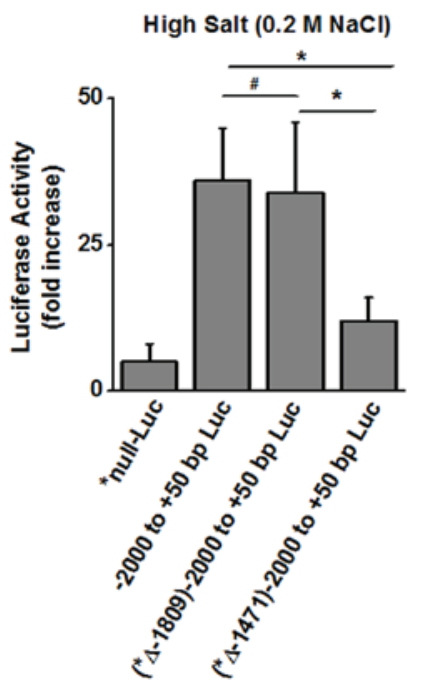

B

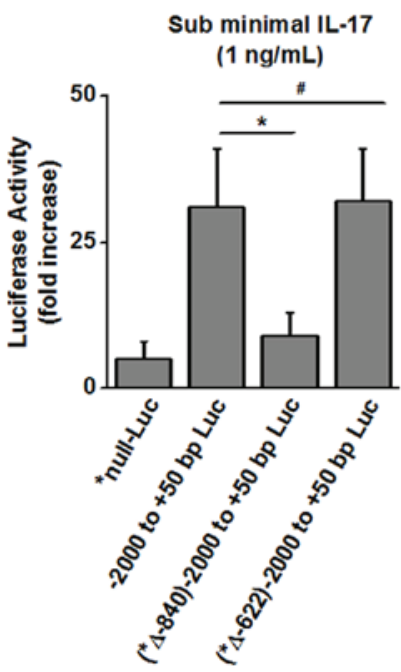

C

High Salt $(0.2 \mathrm{M} \mathrm{NaCl})$

+Sub minimal IL-17 (1 ng/mL)

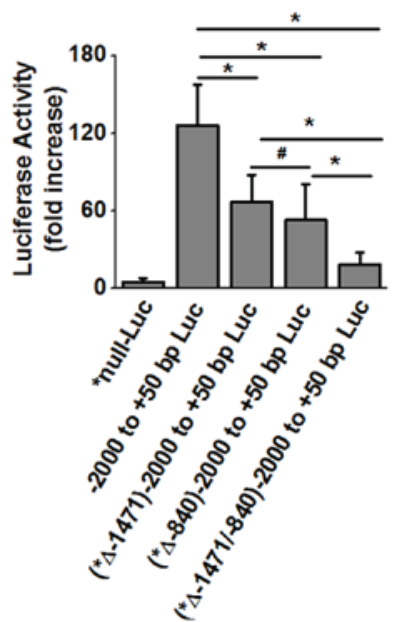

D

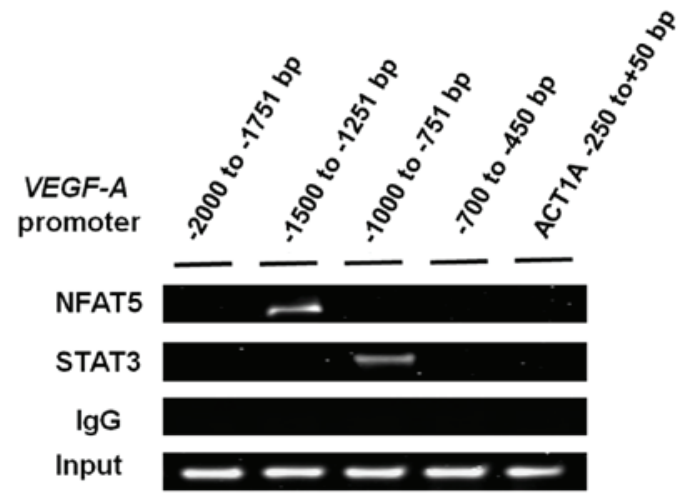

$\mathbf{E}$

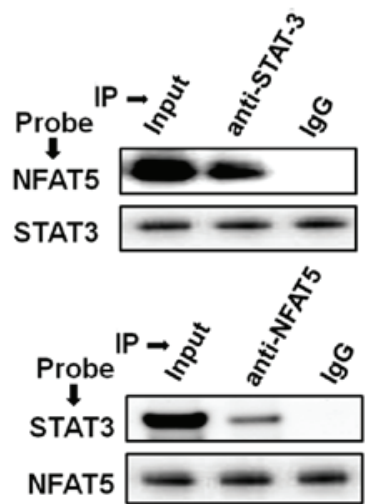

Figure 3. Binding sites of the transcription factors NFAT5 and STAT3 on the VEGF-A promoter to induce downstream gene transcription. (A) Transcription Element Search System-based computational analysis of -2,000 bp upstream of the VEGF-A open reading frame. Putative binding domains for NFAT5 and STAT3 at $-1,809,-1,471,-840$ and -622 bp were predicted to contain consensus sequences on the VEGF-A promoter. MCF-7 cells were transfected with a luciferase reporter driven by constructs of the VEGF-A promoter $\left(-2,000\right.$ to $+50 \mathrm{bp}$; mutation ${ }^{*} \Delta-1,812-11 \mathrm{bp} /-2,000$ to $+50 \mathrm{bp}$; and mutation ${ }^{*} \Delta-1,474-73 \mathrm{bp} /-2,000$ to $+50 \mathrm{bp}$ ) construct, and stimulated with high salt. (B) MCF-7 cells were transfected with luciferase reporters driven by constructs of the VEGF-A promoter $\left(-2,000\right.$ to $+50 \mathrm{bp}$; mutation ${ }^{*} \Delta-843-42 \mathrm{bp} /-2,000$ to $+50 \mathrm{bp}$; and mutation ${ }^{*} \Delta-625-24 \mathrm{bp} /-2,000$ to $\left.+50 \mathrm{bp}\right)$ construct, and stimulated with IL-17. (C) MCF-7 cells were transfected with luciferase reporters driven by constructs of the VEGF-A promoter $(-2,000$ to $+50 \mathrm{bp} ; \mathrm{mutation} * \Delta-1,474-73 \mathrm{bp} /-2,000$ to $+50 \mathrm{bp}$; mutation ${ }^{*} \Delta-843-42 \mathrm{bp} /-2,000$ to $+50 \mathrm{bp}$; or both mutations) construct, and stimulated with high salt and IL-17. Luciferase activity was measured $48 \mathrm{~h}$ after transfection and normalized to a Renilla luciferase internal control. The numbers indicate fold-change over the control vector. (D) VEGF-A promoter with binding sites for NFAT5 and STAT3. The four black horizontal bars represent the regions amplified by polymerase chain reaction with specific primers for the $-2,000$ to $-1,751 \mathrm{bp},-1,500$ to $-1,251 \mathrm{bp},-1,000$ to $-751 \mathrm{bp}$ and -700 to $-450 \mathrm{bp}$ regions of the VEGF-A promoter, and the negative control -250 to $+50 \mathrm{bp}$ region of the ACT1a promoter. Chromatin was immunoprecipitated with anti-NFAT5, anti-STAT3 or isotype control immunoglobulin G antibodies from MCF-7 cells following stimulation with both high salt and IL-17. The first three lanes represent chromatin-immunoprecipitation, while the fourth lane represents input chromatin. (E) Co-immunoprecitation of the protein-complex extracted by anti-STAT3 and anti-NFAT5 antibodies, and western blot analysis to probe with the opposite antibody (upper panel, probed with NFAT5 antibody and protein complex pulled-down with anti-STAT3 antibody; lower panel, probed with STAT3 antibody and protein complex pulled-down with anti-NFAT5 antibody). Data are represented as mean values \pm standard error of the mean from four independent experiments. Statistical significance was analyzed with the Student's $t$ test, ${ }^{*} \mathrm{P}<0.05$; ${ }^{\prime} \mathrm{P}>0.05$. Luc, luciferase; IL, interleukin; ACT1a, actin-1a; NFAT, nuclear factor of activated T-cells; STAT, signal transducer and activator of transcription; Ig, immunoglobulin; VEGF, vascular endothelial growth factor.

and STAT3 synergistically interact and are part of a larger transcription-regulatory complex enhancing the VEGF-A gene expression.

Enhanced cell migration following activation of NHAECs with VEGF-A supernatant. As VEGF-A has been implicated in tumor cell migration, the potential upregulation of cell migration and surface proteins that mediate cell migration in NHAECs was determined (29). MCF-7 cells were pre-stimulated for $48 \mathrm{~h}$ with high salt, sub-minimal IL-17 or both, and later washed. Supernatant collected from $24 \mathrm{~h}$ post-stimulation cultured cells under basal medium conditions was used to determine the migration efficiency of NHAECs. Cell migration was studied utilizing a migration chamber with NHAECs coated in the top chamber with serum-starved medium, while the bottom chamber was filled with supernatant collected from $24 \mathrm{~h}$ post-stimulated MCF-7 cells. As shown in Fig. 4A and B, following treatment of NHAECs for $24 \mathrm{~h}$ with supernatant of MCF-7 cells subjected to combined pre-stimulation with high salt and IL-17, there was increased migration of NHAECs [optical density (OD), 0.62 \pm 0.19 ] compared with individual stimulation with only high salt $(\mathrm{OD}, 0.28 \pm 0.09)$ or sub-minimal IL-17 (OD, 0.21 \pm 0.07$)$. It is important to note that there was 
A

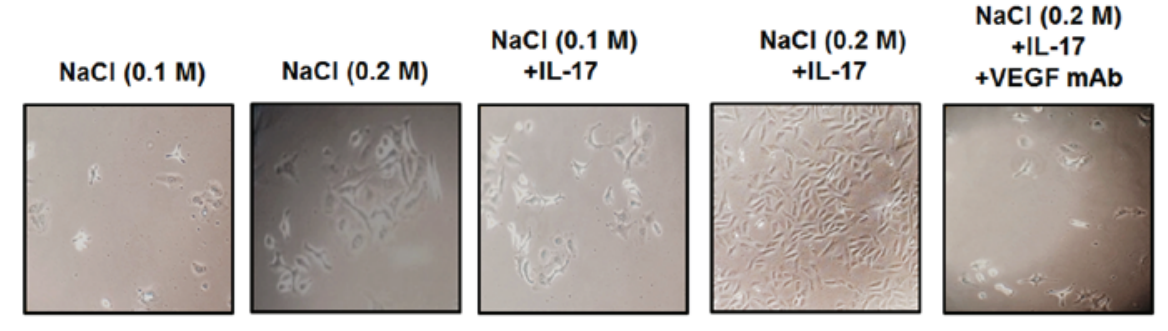

C

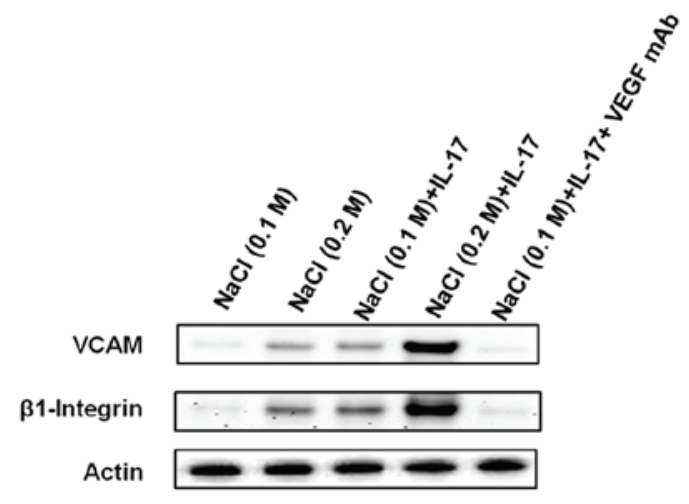

$\mathbf{F}$

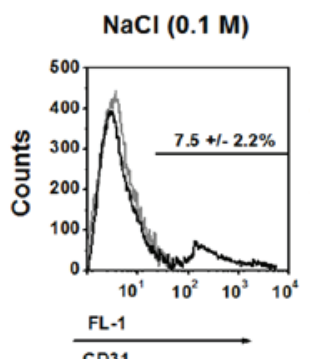

$\mathrm{NaCl}(0.2 \mathrm{M})$

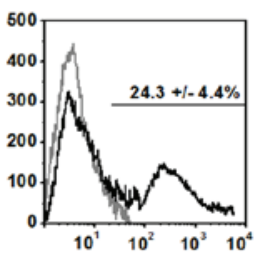

D
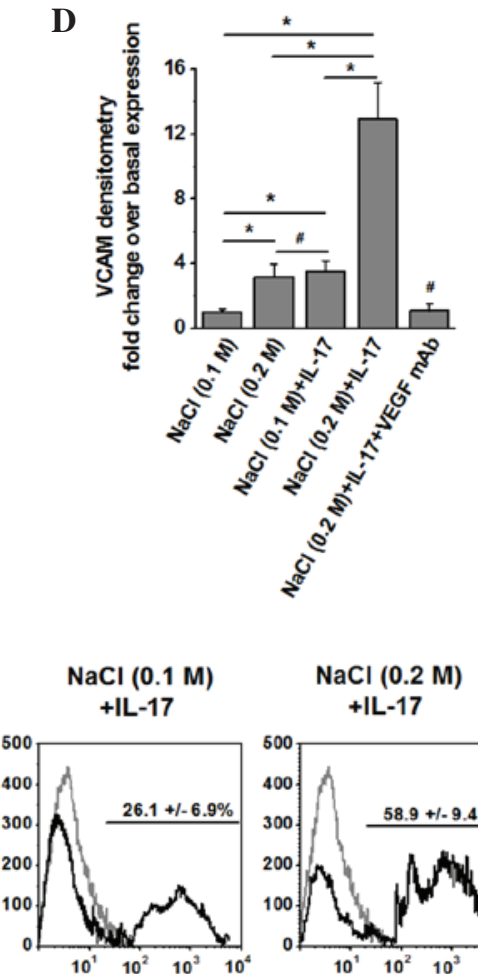

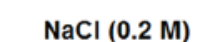

+ IL-17

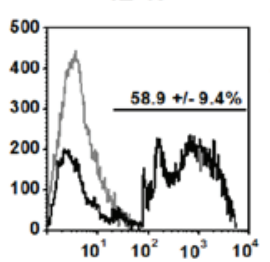

B

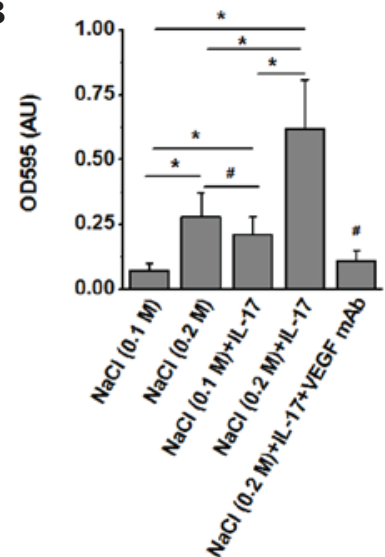

$\mathbf{E}$

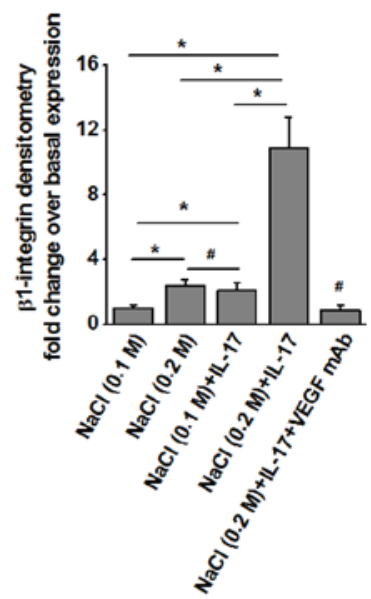

$\mathrm{NaCl}(0.2 \mathrm{M})$

$+\mathrm{IL}-17$

+ VEGF mAb

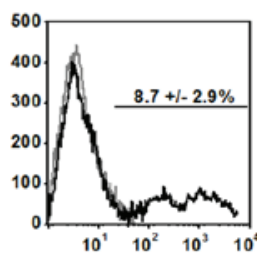

Figure 4. Induction of cell migration and migration-specific protein expression following activation of NHAECs with VEGF-A-rich supernatant. (A) Cell migration analysis after $24 \mathrm{~h}$ of culture in the migration chambers. The top chamber was coated with NHAECs placed in serum-starved medium. The lower chamber was filled with fresh 24-h supernatant from MCF-7 cells following pre-stimulation for $48 \mathrm{~h}$ with high salt, IL-17 or both. To determine the specific role of VEGF-A, in the fifth panel, the lower chamber was filled with supernatant (as described above) with both high salt and IL-17, along with VEGF-A neutralization with immunoglobulin G2b monoclonal antibody at 1:1,000 dilution. (B) Optical density at $595 \mathrm{~nm}$ of the cells collected from the bottom chamber following $24 \mathrm{~h}$ of culture (C) Western blot analysis of NHAECs probed for VCAM (110 kDa) and $\beta 1$ integrin (130 kDa) following treatment with supernatant from MCF-7 cells stimulated with high salt, IL-17 or both for $24 \mathrm{~h}$. (D) Densitometry analysis of the western blotting results for VCAM normalized to basal expression. (E) Densitometry analysis of the western blotting results for $\beta 1$ integrin normalized to basal expression. (F) Flow cytometry analysis of the expression of CD31 on NHAECs subjected to the stimulation conditions mentioned above. FL-1 refers to the single fluorescence channel maintained for phosphatidylethanolamine-labeled probing of CD31. The isotype control is represented by the grey line, while CD31 is represented by the black line. Data are presented as mean values \pm standard error of the mean from four independent experiments. Statistical significance was analyzed by the Student's $t$ test, " $\mathrm{P}<0.05$; ${ }^{\text {"P }}>0$.05. IL, interleukin; VEGF, vascular endothelial growth factor; mAb, monoclonal antibody; OD, optical density; AU, arbitrary unit; VCAM, vascular cell adhesion protein; $\mathrm{CD}$, cluster of differentiation; NHAECs, normal human aortic endothelial cells.

a significant inhibition of NHAEC migration when blocked with anti-VEGF-A monoclonal IgG2b antibody (1:1,000 dilution; cat no. MAB293; R\&D Systems) addition to the supernatant collected from high salt and IL-17-co-treated MCF-7 cells. This supports the hypothesis that cell migration was mediated by VEGF-A secreted from pre-stimulated MCF-7 cells. Furthermore, analysis of the expression of the migratory molecules VCAM (Fig. 4C), $\beta 1$ integrin (Fig. 4D) and CD31 (Fig. 4E) demonstrated enhanced expression of these migratory molecules in NHAECs upon treatment with supernatant from pre-stimulated MCF-7 cells with both high salt and sub-minimal IL-17. These findings confirm that high salt synergised with the pro-inflammatory cytokine-mediated expression of the stress factor VEGF-A. 


\section{Discussion}

Although high salt has been traditionally associated with cardiovascular diseases, recent evidence suggests that high salt levels also increase the risk of cancer (13). The tumor microenvironment is known to have high concentrations of several inflammatory cytokines, including IL-6, IL-17 and $\mathrm{TNF} \alpha(30)$. High salt is a potent inducer of chronic inflammatory response through the activation of reactive oxygen and nitrogen species (31). Furthermore, chronic inflammation is considered a key initiator for several solid tumors, including breast cancer (2). As early as in the 1980s, high salt and sodium transporters in the tumor tissue were suggested to play a critical role in breast cancer progression and metastasis (17). More recently, a direct inflammatory effect of salt on immune cells such as T-cells and macrophages has been reported $(32,33)$. However, the exact molecular mechanisms by which high salt induces inflammation in the tumor microenvironment are not yet defined.

The role of osmotic stress in inflammatory processes has been extensively suggested in the scientific literature (34). Culture of human peripheral blood cells under hyperosmotic conditions (330-410 mOsm/ $/ \mathrm{kg} \mathrm{H}_{2} \mathrm{O}$ ) has been shown to induce expression of pro-inflammatory cytokines such as IL-1 and IL-8 (35). Notably, patients with Crohn's disease, an inflammatory bowel disease, present with substantially higher osmolality of the faecal fluid compared with control subjects ( 490 vs. $340 \mathrm{mOsm} / \mathrm{kg} \mathrm{H}_{2} \mathrm{O}$ ), which strongly correlates with the intestinal histopathological score (36). In the tumor microenvironment, osmotic stress is considered to trigger receptor tyrosine kinases such as epidermal growth factor receptor, resulting in activation of the erbB-2/neu proto-oncogene (37). All the above lines of evidence suggest that hypernatremia or high sodium induce osmotic stress, which in-turn leads to an inflammatory response. The current study attempted to evaluate the direct inflammatory effect of high salt on hyperosmolarity-induced events (by performing control equimolar mannitol studies), in order to demonstrate that high salt in the cell microenvironment could directly induce expression of VEGF, a known inflammatory biomarker (10). However, the current results do not completely preclude a high salt-mediated, osmotic-stress-induced VEGF expression, which requires further studies.

Although VEGF was originally discovered as a vascular and endothelial-activating factor, several studies have conclusively suggested its critical role in tumor cell progression and metastasis (10). Several isoforms of VEGF have been reported, including $\mathrm{VEGF}_{121}, \mathrm{VEGF}_{165}$ and $\mathrm{VEGF}_{189}$, (38). In addition, cell-specific VEGF isoforms, including VEGF-A (present in the majority of cell types) (10), VEGF-B (present in neurons and retina) (39) and VEGF-C (present in macrophages) (40) have been reported. It is important to note that anti-VEGF monoclonal antibody-based therapeutic strategies are currently employed to treat cancers (41). It has also been suggested that direct stimulation of tumor cells by VEGF may inhibit apoptosis and increase their resistance to conventional chemotherapy and radiotherapy administered in cancer treatment (42). Therefore, understanding the mechanisms of expression of VEGF is crucial for anti-cancer therapeutic success. It has been well documented that VEGF exerts autocrine and paracrine pro-cancer effects in breast cancer through activation of cancer-specific AKT/phosphoinositide 3-kinase signaling mechanisms (43). In the present study, the potential role of high salt in the presence of pro-inflammatory cytokines towards induction of VEGF has been investigated. Notably, the present results support the previous reports that inflammatory stimulus induces VEGF expression in MCF-7 breast cancer cells (Fig. 1). Therefore, the present authors propose a novel role for high salt in the tumor microenvironment as an important mediator of VEGF expression. Furthermore, this expressed VEGF was observed to be critical for endothelial cell migration (Fig. 4). Taken together, the present data suggest that high salt plays a key inflammatory role in VEGF-mediated cancer cell proliferation.

The transcription factor NFAT5 is the most recently identified member of the NFAT family (44). Originally, NFAT5 was termed TonEBP or osmotic response element-binding protein (34). In humans, previous studies addressing the function of NFAT5 were primarily focused on the kidney medulla, since renal cells are physiologically exposed to highly elevated interstitial osmolalities (34). NFAT5 is considered to exert an osmoprotective function in the kidney (33). However, a number of studies supported the notion that NFAT5 is important in immune responses and lymphocyte activation (45). A recent study by Remo et al (28), utilizing in silico modeling and gene expression analysis on breast cancer patients $(\mathrm{n}=197)$, reported an enhanced expression of NFAT5 in inflammatory breast cancer. In line with that study, the present findings have demonstrated that high salt induces VEGF expression through specific upregulation of the transcription levels of NFAT5 (Figs. 2 and 3), a known key molecule in breast cancer (27). In addition, the present study identified a putative NFAT5 binding domain on the VEGF-A promoter at $-1,471$ bp upstream of the VEGF-A coding gene (Fig. 3). These data clearly suggest that high salt mediates a direct inflammatory response in the cancer microenvironment.

The present study has demonstrated that high salt synergises with IL-17, a pro-inflammatory cytokine, towards the expression of the inflammatory molecule VEGF-A (27). The role of IL-17 in cancer progression is well established. Several reports, including a previous study by the present authors, have demonstrated that IL-17 exerts its inflammatory response through activation of the STAT3 transcription factor signaling pathway (23). STATs comprise a family of cytoplasmic transcription factors that mediate intracellular signaling, which is usually generated by membrane receptor-ligand interactions (45). Numerous studies have demonstrated constitutive activation of STAT3 in a wide variety of human tumors (46). There is an increasing body of evidence suggesting that aberrant STAT3 signaling promotes initiation and progression of human cancers (46). Suppression of STAT3 activation has been reported to induce tumor cell death by apoptosis (45). In line with previous reports, the present authors have identified a putative STAT3 binding domain (Fig. 3) at -840 bp upstream of the VEGF-A coding gene. Furthermore, the results of the luciferase reporter assay conducted in the present study strongly suggest that high salt exerts its synergistic effect with the pro-inflammatory cytokine IL-17 through activation of two independent but synchronous signaling pathways via NFAT5 and STAT3, 
in order to induce the expression of VEGF-A. However, the current study has limitations due to the experimental use and analysis of only one breast cancer cell line. Nonetheless, the authors consider that the conclusions of the present study are applicable to other solid tumors, which requires further validation in other tumor cell lines (particularly breast cancer), along with animal model studies.

In conclusion, in spite of significant advances, current anti-cancer therapies have a great scope for improvement (6). The current data suggest an important role for NFAT5 and STAT3 signaling in high salt-mediated cancer cell proliferation and migration. The authors propose a low-salt diet, and supplementing anti-VEGF therapy with anti-NFAT5 and anti-STAT3 therapies, as a future direction for efficient cancer therapy. However, further clinical and basic biomedical studies are required to validate these observations.

\section{Acknowledgements}

The present study was supported by the Vanderbilt University (Nashville, TN, USA) and Tennessee State University (Nashville, TN, USA) Cancer Partnership (National Institutes of Health, Bethesda, MA, USA; grant no. 5U54CA163066). The authors would like to thank the members of the Department of Biological Sciences of Tennessee State University for their kind support on the present project.

\section{References}

1. Balkwill $\mathrm{F}$ and Mantovani A: Inflammation and cancer: Back to Virchow? Lancet 357: 539-545, 2001.

2. Colotta F, Allavena P, Sica A, Garlanda C and Mantovani A: Cancer-related inflammation, the seventh hallmark of cancer: Links to genetic instability. Carcinogenesis 30: 1073-1081, 2009.

3. Grivennikov SI, Greten FR and Karin M: Immunity, inflammation, and cancer. Cell 140: 883-899, 2010.

4. Hussain SP, Hofseth LJ and Harris CC: Radical causes of cancer. Nat Rev Cancer 3: 276-285, 2003.

5. Hanahan D and Weinberg RA: The hallmarks of cancer. Cell 100: 57-70, 2000.

6. Dranoff G: Cytokines in cancer pathogenesis and cancer therapy. Nat Rev Cancer 4: 11-22, 2004.

7. Chang SH, Mirabolfathinejad SG, Katta H, Cumpian AM, Gong L, Caetano MS, Moghaddam SJ and Dong C: T helper 17 cells play a critical pathogenic role in lung cancer. Proc Natl Acad Sci USA 111: 5664-5669, 2014.

8. He D, Li H, Yusuf N, Elmets CA, Athar M, Katiyar SK and $\mathrm{Xu} \mathrm{H}$ : IL-17 mediated inflammation promotes tumor growth and progression in the skin. PLoS One 7: e32126, 2012.

9. Gaffen SL: Structure and signalling in the IL-17 receptor family. Nat Rev Immunol 9: 556-567, 2009.

10. Goel HL and Mercurio AM: VEGF targets the tumour cell. Nat Rev Cancer 13: 871-882, 2013.

11. Chung J, Bachelder RE, Lipscomb EA, Shaw LM and Mercurio AM: Integrin (alpha 6 beta 4) regulation of eIF-4E activity and VEGF translation: A survival mechanism for carcinoma cells. J Cell Biol 158: 165-174, 2002.

12. Stephenson GD and Rose DP: Breast cancer and obesity: An update. Nutr Cancer 45: 1-16, 2003.

13. Strnad M: Salt and cancer. Acta Med Croatica 64: 159-161, 2010 (In Croatian).

14. Zhang F, Tang Z, Hou X, Lennartsson J,Li Y, Koch AW, Scotney P, Lee C, Arjunan P, Dong L, et al: VEGF-B is dispensable for blood vessel growth but critical for their survival, and VEGF-B targeting inhibits pathological angiogenesis. Proc Natl Acad Sci USA 106: 6152-6157, 2009.

15. Mozaffari MS, Patel C, Ballas C and Schaffer SW: Effects of excess salt and fat intake on myocardial function and infarct size in rat. Life Sci 78: 1808-1813, 2006.
16. Ketonen J and Mervaala E: Effects of dietary sodium on reactive oxygen species formation and endothelial dysfunction in low-density lipoprotein receptor-deficient mice on high-fat diet. Heart Vessels 23: 420-429, 2008.

17. Sparks RL, Pool TB, Smith NK and Cameron IL: Effects of amiloride on tumor growth and intracellular element content of tumor cells in vivo. Cancer Res 43: 73-77, 1983.

18. Tsugane S, Sasazuki S, Kobayashi M and Sasaki S: Salt and salted food intake and subsequent risk of gastric cancer among middle-aged Japanese men and women. Br J Cancer 90: 128-134, 2004.

19. Tiriveedhi V, Upadhya GA, Busch RA, Gunter KL, Dines JN, Knolhoff BL, Jia J, Sarma NJ, Ramachandran S, Anderson CD, et al: Protective role of bortezomib in steatotic liver ischemia/reperfusion injury through abrogation of MMP activation and YKL-40 expression. Transpl Immunol 30: 93-98, 2014.

20. Sarma NJ, Tiriveedhi V, Crippin JS, Chapman WC and Mohanakumar T: Hepatitis C virus-induced changes in microRNA 107 (miRNA-107) and miRNA-449a modulate CCL2 by targeting the interleukin- 6 receptor complex in hepatitis. J Virol 88: 3733-3743, 2014.

21. Tiriveedhi V, Takenaka M, Sarma NJ, Gelman AG and MohanakumarT: Anti-major histocompatibility complex-induced obliterative airway disease: Selective role for CD4 and CD8 $\mathrm{T}$ cells in inducing immune responses to self-antigens. J Heart Lung Transplant 32: 714-722, 2013.

22. Barr MP, Gray SG, Gately K, Hams E, Fallon PG, Davies AM, Richard DJ, Pidgeon GP and O'Byrne KJ: Vascular endothelial growth factor is an autocrine growth factor, signaling through neuropilin-1 in non-small cell lung cancer. Mol Cancer 14: 45, 2015.

23. Amara S, Lopez K, Banan B, Brown SK, Whalen M, Myles E, Ivy MT, Johnson T, Schey KL and Tiriveedhi V: Synergiztic effect of pro-inflammatory TNF $\alpha$ and IL-17 in periostin mediated collagen deposition: Potential role in liver fibrosis. Mol Immunol 64: 26-35, 2015.

24. Tiriveedhi V, Gelman AE and Mohanakumar T: HIF-1 $\alpha$ signaling by airway epithelial cell K- $\alpha 1$-tubulin: Role in fibrosis and chronic rejection of human lung allografts. Cell Immunol 273: 59-66, 2012.

25. Tiriveedhi V, Takenaka M, Ramachandran S, Gelman AE, Subramanian V, Patterson GA and Mohanakumar T: T regulatory cells play a significant role in modulating MHC class I antibody-induced obliterative airway disease. Am J Transplant 12: 2663-2674, 2012.

26. Rao X, Huang X, Zhou Z and Lin X: An improvement of the $2^{\wedge}$ (-delta delta $\mathrm{CT}$ ) method for quantitative real-time polymerase chain reaction data analysis. Biostat Bioinforma Biomath 3:71-85, 2013.

27. Chung AS, Wu X, Zhuang G, Ngu H, Kasman I, Zhang J, Vernes JM, Jiang Z, Meng YG, Peale FV, et al: An interleukin-17-mediated paracrine network promotes tumor resistance to anti-angiogenic therapy. Nat Med 19: 1114-1123, 2013.

28. Remo A, Simeone I, Pancione M, Parcesepe P, Finetti P, Cerulo L, Bensmail H, Birnbaum D, Van Laere SJ, Colantuoni V, et al: Systems biology analysis reveals NFAT5 as a novel biomarker and master regulator of inflammatory breast cancer. J Transl Med 13: 138, 2015.

29. Wang Y, Zang QS, Liu Z, Wu Q, Maass D, Dulan G, Shaul PW, Melito L, Frantz DE, Kilgore JA, et al: Regulation of VEGF-induced endothelial cell migration by mitochondrial reactive oxygen species. Am J Physiol Cell Physiol 301: C695-C704, 2011.

30. Lu H, Ouyang W and Huang C: Inflammation, a key event in cancer development. Mol Cancer Res 4: 221-233, 2006.

31. Azak A, Huddam B, Gonen N, Yilmaz SR, Kocak G and Duranay M: Salt intake is associated with inflammation in chronic heart failure. Int Cardiovasc Res J 8: 89-93, 2014.

32. Wu C, Yosef N, Thalhamer T, Zhu C, Xiao S, Kishi Y, Regev A and Kuchroo VK: Induction of pathogenic TH17 cells by inducible salt-sensing kinase SGK1. Nature 496: 513-517, 2013.

33. Jantsch J, Schatz V, Friedrich D, Schröder A, Kopp C, Siegert I, Maronna A, Wendelborn D, Linz P, Binger KJ, et al: Cutaneous $\mathrm{Na}+$ storage strengthens the antimicrobial barrier function of the skin and boosts macrophage-driven host defense. Cell Metab 21: 493-501, 2015.

34. Neuhofer W: Role of NFAT5 in inflammatory disorders associated with osmotic stress. Curr Genomics 11: 584-590, 2010 
35. Shapiro L and Dinarello CA: Hyperosmotic stress as a stimulant for proinflammatory cytokine production. Exp Cell Res 231 354-362, 1997.

36. Schilli R, Breuer RI, Klein F, Dunn K, Gnaedinger A, Bernstein J, Paige $M$ and Kaufman M: Comparison of the composition of faecal fluid in Crohn's disease and ulcerative colitis. Gut 23: 326-332, 1982

37. King CR, Borrello I, Porter L, Comoglio P and Schlessinger J: Ligand-independent tyrosine phosphorylation of EGF receptor and the erbB-2/neu proto-oncogene product is induced by hyperosmotic shock. Oncogene 4: 13-18, 1989.

38. Pagès $\mathrm{G}$ and Pouysségur $\mathrm{J}$ : Transcriptional regulation of the vascular endothelial growth factor gene-a concert of activating factors. Cardiovasc Res 65: 564-573, 2005.

39. Poesen K, Lambrechts D, Van Damme P, Dhondt J, Bender F, Frank N, Bogaert E, Claes B, Heylen L, Verheyen A, et al: Novel role for vascular endothelial growth factor (VEGF) receptor-1 and its ligand VEGF-B in motor neuron degeneration. J Neurosci 28 : 10451-10495, 2008.

40. Wiig H, Schröder A, Neuhofer W, Jantsch J, Kopp C, Karlsen TV, Boschmann M, Goss J, Bry M, Rakova N, et al: Immune cells control skin lymphatic electrolyte homeostasis and blood pressure. J Clin Invest 123: 2803-2815, 2013.
41. Harmey JH and Bouchier-Hayes D: Vascular endothelial growth factor (VEGF), a survival factor for tumour cells: Implications for anti-angiogenic therapy. Bioessays 24: 280-283, 2002.

42. Gorski DH, Beckett MA, Jaskowiak NT, Calvin DP, Mauceri HJ, Salloum RM, Seetharam S, Koons A, Hari DM, Kufe DW and Weichselbaum RR: Blockage of the vascular endothelial growth factor stress response increases the antitumor effects of ionizing radiation. Cancer Res 59: 3374-3378, 1999.

43. Pidgeon GP, Barr MP, Harmey JH, Foley DA and Bouchier-Hayes DJ: Vascular endothelial growth factor (VEGF) upregulates BCL-2 and inhibits apoptosis in human and murine mammary adenocarcinoma cells. Br J Cancer 85: 273-288, 2001.

44. Mancini $M$ and Toker A: NFAT proteins: Emerging roles in cancer progression. Nat Rev Cancer 9: 810-820, 2009.

45. Berga-Bolaños R, Drews-Elger K, Aramburu J and López-Rodríguez C: NFAT5 regulates T lymphocyte homeostasis and CD24-dependent $\mathrm{T}$ cell expansion under pathologic hypernatremia. J Immunol 185: 6624-6635, 2010.

46. Yu H, Pardoll D and Jove R: STATs in cancer inflammation and immunity: A leading role for STAT3. Nat Rev Cancer 9: 798-809, 2009. 